\title{
USO DA BIODIVERSIDADE E A PAISAGEM EM RESEX'S NO AMAZONAS
}

\author{
Ana Claudia Narbaes de Carvalho \\ Mestranda do Programa de Pós-graduação em Geografia - UFAM \\ Universidade Federal do Amazonas \\ claudianarbaes@hotmail.com \\ Reinaldo Correa Costa \\ Pesquisador Doutor do Instituto Nacional de Pesquisas da Amazônia \\ reiccosta@gmail.com
}

\begin{abstract}
RESUMO: O presente trabalho tem por objetivo analisar o processo de uso da biodiversidade nas Reservas Extrativistas do Rio Jutaí e Médio Juruá a partir da intersecção teórica e metodológica entre Geossistema e Formação Sócio-espacial. Neste sentido, será realizado um levantamento bibliográfico acerca da teoria geossistêmica e do conceito de formação sócio-espacial relacionando-os com a realidade empiricamente observada a partir dos trabalhos de campo realizados nas mesmas. A biodiversidade identificada se caracteriza como cultivada, os quintais agroflorestais e produtos coletados no meio natural, porém com uso dos sistemas naturais, como o clima, o solo, entre outros serviços ambientais. Dentre os produtos identificados e comercializados está o óleo de andiroba e manteiga de murumuru na Resex do Médio Juruá (AM) e a comercialização da farinha de mandioca na Resex do Rio Jutaí. Ambos os processos que envolvem a cultura, a economicidade, a estrutura política e os sistemas naturais, são regidas a partir de um contexto específico de cada uma dessas unidades territoriais de análise e consequentemente cada uma tem sua paisagem como gênese, herança e indicador.
\end{abstract}

Palavras-chave: Biodiversidade, Resex, Formação Sócio-espacial

\section{INTRODUÇÃO}

Em ambas as unidades de conservação os moradores trabalham com os quintais agroflorestais e a produção de farinha de mandioca. Para distinguir a realidade, seja da Reserva extrativista ou do uso da biodiversidade, ou até mesmo de todos estes elementos, faz-se presente a necessidade de uma abordagem metodológica que busque a totalidade. Para identificar a realidade de como os processos naturais, sociais e econômicos se concretizam no Uso da biodiversidade das Reservas Extrativistas, desse modo faz-se necessário o abarcamento da totalidade. Identificar e analisar como estes fenômenos se divergem e/ou ao mesmo tempo interagem entre si, isso é possível a partir do todo, na qual todos estes fenômenos de certa forma compõem uma totalidade. 


\section{MATERIAIS E MÉTODOS}

A partir da concepção teórica e metodológica, a biodiversidade está inserida na intersecção entre os geossistemas e a formação sócio-espacial, que busque a totalidade. No geossistema onde estão presentes diferentes elementos da natureza relacionados ao potencial ecológico, exploração biológica e também ação antrópica, conforme Bertrand (2004), assim como o planejamento e o impacto nos territórios. Para Santos (1977) a formação sócio-espacial é para o a abordagem da totalidade, nem nosso caso o processo de apropriação e uso de elementos da natureza (a biodiversidade), e aqui envolve o modo de vida dos grupos sociais locais, onde estão presentes distintas racionalidades e objetividades, conforme a dinâmica da natureza (geossistemas) e o as formas de uso da mesma pelos modos de vida da resex, uma relação sociedade natureza que é fruto de uma formação sócio espacial especifica.

Ao abordar biodiversidade um termo muito abrangente, é importante ressaltar a qual fazemos parte, de nossa parte estudar todo o conjunto de elementos, funções e interrelações presentes na biodiversidade das resex's. Neste contexto, utilizaremos como exemplos, processos identificados na Reserva Extrativista do Médio Juruá (AM) e Reserva Extrativista do Rio Jutaí (AM) destacaremos o uso da biodiversidade estudado envolve o uso de plantas cultivadas em quintais agroflorestais e a mandioca para a produção de farinha de mandioca, também o trataremos do extrativismo como da andiroba e do murumuru.

\section{RESULTADOS E DISCUSSÕES}

A biodiversidade (cultivada ou não) faz parte do processo de reprodução do modo de vida dos moradores na Resex do Médio Juruá, dando Ihe suporte para sua existência (social, econômica e política). Os quintais agroflorestais são cultivados em uma área em torno da residência do morador, nesta área existem árvores frutíferas, hortaliças, plantas medicinais, entre outras. Estas plantas tem determinada função: alimentícia, medicinal, em alguns casos econômicos, nelas estão a partir da matéria prima a forma recurso natural, isto é, valor de uso, valor de troca.

No caso da função alimentícia, situa-se num plano de complementação de produtos cultivados em outras áreas no lote, como a roça. Já no caso das plantas com uso medicinal, as diferentes enfermidades decorrentes de várias origens, utilizam as plantas medicinais, com uso de chás, xaropes, "garrafadas", entre outras. Observa-se então que não se trata do uso de uma biodiversidade natural, mas uma biodiversidade cultivada. Logo o uso desta biodiversidade é como uma prática territorial dentro da unidade familiar, isto é, uso da biodiversidade como uso do território que é portador de uma paisagem, herança de da natureza e de processo dos modos de vida e como indicador da sanidade dos ambientes e dos ritmos da natureza.

Dentre as árvores frutíferas citadas nas entrevistas realizadas nas Resexs estão o cupuaçuzeiro, a pupunheira, a bananeira, o coqueiro, o ingazeiro, a goiabeira, a mangueira, entre outras. No total das espécies vegetais, predominou aquelas trazidas 
de outras áreas, ou seja, de fora da Resex, em relação às nativas, mesmo assim elas são importantes no processo de conservação da diversidade vegetal local. Dentre algumas espécies nativas citadas presentes em alguns quintais florestais estão: carapanaúbeira, copaíbeira, o açaizeiro e andirobeiras. Entretanto, na maioria dos casos, a carapanaúba, a copaíba, o açaí e andiroba são encontrados em mata fechada, isto é, na floresta natural.

Nas entrevistas, os moradores citavam como capoeirinha (processo de sucessão florestal) a vegetação que se encontrava em meio a sua plantação e de pequeno porte. Já a capoeira consistia em uma vegetação de médio porte, onde há presença de muitos cipós (alguns cortantes quando entram em contato com a pele), sendo muito difícil caminhar em meio a esta etapa de vegetação. Nestas áreas geralmente o morador já desenvolveu ou desenvolve algum trabalho agrícola como a roça, abandonando a área depois de algum tempo de exploração para pousio (regeneração natural). Com relação ao capoeirão no entendimento dos moradores é a área que ainda não desenvolveu nenhum trabalho de derrubada das árvores, onde se coleta frutos de árvores nativas da floresta ou plantas medicinais, para fins geralmente terapêuticos.

Uma lógica presente refere-se ao consorciamento de culturas. De acordo com Woortmann e Woortmann (1997) "o consorciamento é outra forma de organizar o espaço e o tempo destinados ao roçado e merece um tratamento detalhado (...). Esses subespaços são organizados em função de um produto-referencia. $O$ fato de o produto referencia caracterizar determinado espaço ou sistema de cultivo não significa que se adote o cultivo solteiro". Ou seja, em algumas áreas de roças não são cultivados apenas uma espécie agrícola, a "escolha dos produtos a serem consorciados obedece ao que poderíamos chamar principio de alternância".

\section{CONCLUSÕES}

Os quintais agroflorestais caracterizados como uma biodiversidade não natural, mas cultivada (humanizada, trabalhada), nem por isso perde sua importância social e biológica para o grupo social que vive no lugar. São cultivados em torno das residências dos moradores, onde são encontradas diferentes tipos de espécies vegetais. Nestas áreas não se encontram apenas espécies trazidas de outros lugares, mas espécies vegetais nativas, ou seja, se tornam importantes na conservação da diversidade local. No processo de uso da biodiversidade dos quintais, um tipo específico de paisagem, está o modo de vida dos moradores, e esta prática se caracteriza como prática territorial e expressão da importância da natureza reprodução dos modos de vida internos a resex e às cadeias produtivas que extrapolam os limites da resex. 
USO DA BIODIVERSIDADE E A PAISAGEM EM RESEX'S NO AMAZONAS

\section{REFERÊNCIAS}

BERTRAND, G. Paisagem e Geografia Física Global: Esboço Metodológico. Revista Ra'ega, № 8, Curitiba, 2004.

SANTOS, M.. Sociedade e Espaço: A Formação Social como teoria e como método. In: Boletim Paulista de Geografia, São Paulo, 1977.

WOORTMANN, E. F.; WOORTMANN, K. O trabalho da Terra: A lógica e a simbólica da lavoura camponesa. Editora UNB, Brasília, 1997. 